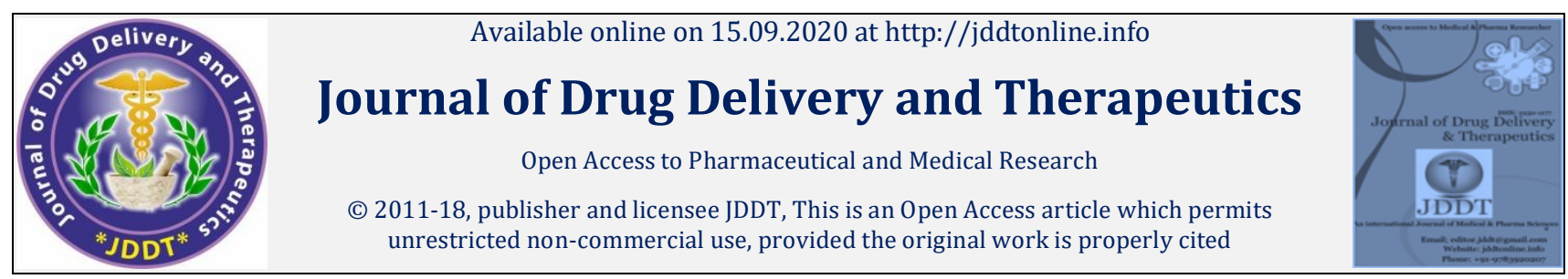

Open Access

Review Article

\title{
Psoriasis: An autoimmune disorder
}

\author{
Purnima Tripathi *, Peeyush Bhardwaj \\ Institute of Pharmacy, Bundelkhand University, Jhansi, 284128, U.P., India
}

\begin{abstract}
Psoriasis is an auto-immune disorder of the skin. It is characterized by the hyperproliferation of keratinocytes. Severity of the disease depends on the body area affected. Both genetic as well as environmental factors are responsible for it. It affects around $2-3 \%$ of world's population. Psoriasis not only causes physical problems, it also affects mental and social well being of the patient. It may also lead to some Comorbidities like heart problems, diabetes, psychological problems, Crohn's disease, etc. Keeping in view the impact it creats in the patient's life, steps should be taken to create awareness of psoriasis. This article attempts to provide a comprehensive view on the psoriasis. It includes the variou s forms of psoriasis with their specific features, causes of psoriasis, diagnosis and assessment tools used, treatments available for its management including topical as well as systemic therapy and associated problems.
\end{abstract}

Keywords: Plaque, Psoriasis, Pustules

Article Info: Received 03 July 2020; Review Completed 19 August 2020; Accepted 28 August 2020; Available online 15 Sep 2020

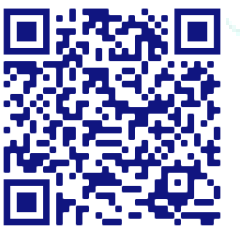

Cite this article as:

Purnima T, Peeyush B, Psoriasis: An autoimmune disorder, Journal of Drug Delivery and Therapeutics. 2020; 10(5):316324 http://dx.doi.org/10.22270/jddt.v10i5.4327

*Address for Correspondence:

Purnima Tripathi, Institute of Pharmacy, Bundelkhand University, Jhansi, 284128, U.P., India

\section{Introduction}

Psoriasis was first recognized in 18081. Ferdinand von Hebra was the first to define psoriasis in the year 1841 . Psoriasis affects approximately 2 to $3 \%$ of the population. Psoriasis is distinguished by the hyperproliferation of keratinocytes secondary to an activated immune system. The peak incidences of psoriasis are observed in 20-39 years of males and 40-59 years of females. The frequency of incidence is equal in both males and females 2. The pathophysiology of psoriasis involves components of the natural and acquired immune systems, genetics, and the environment. Clinically it is recognized as erythematous plaques with non-uniform borders and silvery scales. Whole body is affected but elbows, knees, scalp, and trunk are usually more affected ${ }^{3}$. The Executive Board of WHO in 2013 asked the 67th World Health Assembly Director-General to create awareness of psoriasis 4,5 .

\section{Psoriasis types}

\section{Psoriasis classification}

Psoriasis cannot be classified based on one criterion. The criteria selected are not exclusive to a class (Table1).

Table 1. classification of psoriasis

\begin{tabular}{|l|l|}
\hline Morphological features of Elementary lesions & Pustular, non-pustular, plaque, guttate, gyrate, ostraceous, etc. \\
\hline Degree of inflammation & Mainly inflammatory vs mainly hyperkeratotic \\
\hline Pattern distribution & Extensive, inverse, seborrhoeic, widespread \\
\hline Extent & One site (scalp, nail, etc), many sites, generalized \\
\hline Time of the first onset & Early vs late-onset \\
\hline Velocity of propagation & Stable, unstable, eruptive \\
\hline
\end{tabular}

The table uses various criteria for the classification of psoriasis. 
Psoriasis is mainly classified as psoriasis vulgaris, guttate psoriasis, inverse psoriasis, and pustular psoriasis. If palms and the soles are affected, this is called palmoplantar psoriasis.

\subsection{Psoriasis Vulgaris (chronic stationary psoriasis, plaque-like psoriasis)}

It is the most common form of psoriasis. It covers $90 \%$ of total incidences of psoriasis; in this type papulosquamous plaques are separated from the nearby area by well-defined borders. The plaques are red or yellowish pink in color, with a white or silvery scale border. Plaques could be of varying thickness; and size (Figure 1). Plaques show maximum activity on the borders: rapidly growing lesions may be circular, with clear skin inside this circular area. Generally, plaques are uniformly distributed, but in most cases occur on the outer surface of elbows and knees; scalp, lumbosacral region, and umbilicus. Inactive inflammatory psoriasis, new lesions arise at the location of trauma or pressure (known as Koebner phenomenon) 6,7 .

\subsubsection{Plaque-type (psoriasis vulgaris classified based on phenotype)}

Features of psoriasis may vary with the anatomical position and sometimes according to the age of onset of plaque psoriasis ${ }^{8}$. Henseler and Christophers have observed two different ages for both male and female during which the disease starts: the first one is around 40 years or before it around $75 \%$ of cases occur in this age; and the second one is after 40 years, with a distinguished peak at 55-60 years 9 .

\subsubsection{Plaque-type psoriasis: Chronic plaque psoriasis}

In plaque-type psoriasis lesions are red, scaly, and discoid in shape. The lesions may be small having diameter upto 0.5 $\mathrm{cm}$ or large covering surfaces of the trunk and limbs (Figure 1 ). The plaques are having a well-defined border that separates it from the normal skin. From the longitudinal studies, it was observed that plaques grow 10 by expanding their border, sometimes the growing borders may become circular (Figure. 2) with the normal skin in the center of the plaque. The plaques are having a very clear border with a loose silvery-white scale. These are generally present in the elbows, knees, lumbosacral area, intergluteal cleft, and scalp. Sometimes, plaques may have pustular lesions (known as psoriasis with pustules). It affects about $90 \%$ of total psoriasis patients 5,11

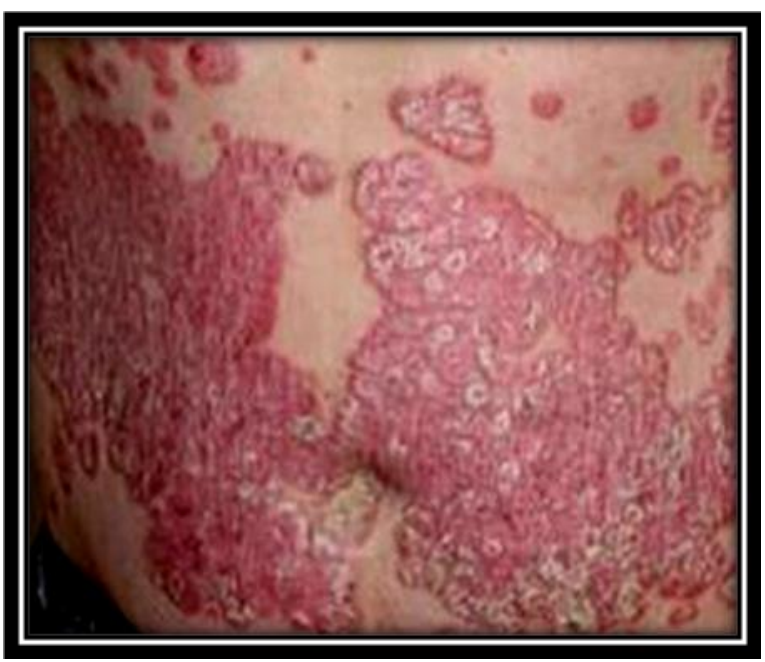

Figure 1. Plaque of Psoriasis Vulgaris

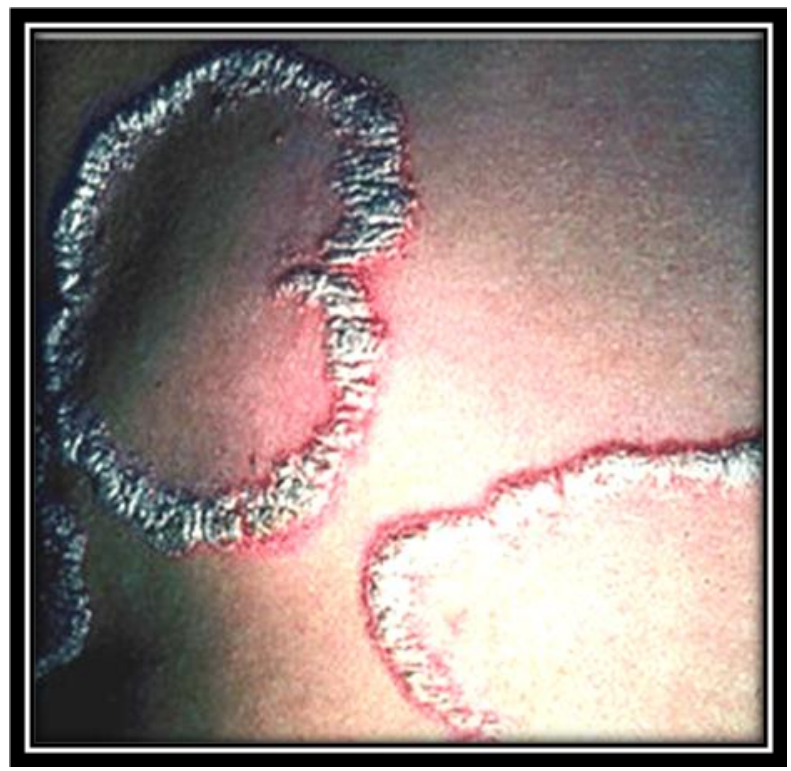

Figure 2. Circular plaques with clear skin in the center

\section{Forms of Psoriasis Vulgaris (PV)}

Psoriasis vulgaris is divided into different forms depending on the site of occurrence. For example flexural psoriasis and sebopsoriasis ${ }^{12}$.

Flexural/intertriginous: Flexural Psoriasis may also be termed as inverse psoriasis or psoriasis of the skin folds because of its location: i.e. underarms, below the breasts, groin area where the skin is folded and between the buttocks. Since sweating and rubbing commonly occurs in these locations which lead to irritation in inverse psoriasis Plaques are thin, with very little scaling and a shining surface. The important clinical features of flexural psoriasis are erythematous plaques with a well-defined border and irregular infiltration, which usually leads to itching and burning ${ }^{13}$. Since humidity and heat are present in these sites, the combination of these two with the local trauma causing factors usually associates with infections caused by dermatophytes and Candida albicans. These may result into the development of psoriasis as per the Koebner phenomenon. The Koebner phenomenon gives indications about disease activity, may be useful in the prognosis, and it associates with early onset of psoriasis ${ }^{14}$. Heinrich Koebner was the first to tell about the kobner phenomenon (18381904). It explains the fact that in people suffering from certain skin diseases, especially psoriasis, new lesions appear, in the traumatized but otherwise normal skin, and the new lesions are clinically and histopathologically identical to those in the diseased skin 15 .

Seborrhoeic: The term seborrhoeic psoriasis (sebopsoriasis) is used because it is similar to seborrhoeic dermatitis in morphological and anatomical positions. Sebopsoriasis may occur with or without plaque psoriasis. It is generally present in nasolabial folds, medial cheeks, ears, eyebrows, hairline, scalp, nose, presternal, and interscapular regions. In sebopsoriasis the lesions are thin, red in color, with a well-defined border and variable degrees of scaling 3 .

\subsection{Guttate psoriasis}

Approximately $2 \%$ of the total psoriatic patients suffer from guttate psoriasis 16. Teardrop Psoriasis, Raindrop Psoriasis, or Psoriasis Exanthematic are the other terms used for Guttate Psoriasis because in Latin 'Guttate' stands for "drop". Characteristic features of the GP are the abrupt appearance of small-sized, reddish in color plaques with scale. Lesions are generally present on the trunk, proximal limbs, and 
scalp. GP can disappear without treatment but can reoccur as plaque psoriasis. GP is usually seen in kids or youngsters having a family history of psoriasis and having streptococcal infection and/or acute stressful life events ${ }^{17}$. Guttate flares are commonly seen in psoriasis vulgaris (PV) patients. From these observations, an indication of the pathogenic relation between GP and PV18 can be obtained. GP often associates with a streptococcal throat infection or an increase in antistreptococcal serum titer before it appears 16,19 .

Pustular psoriasis: Approximately $20 \%$ of psoriasis patients are reported to have lesions with pustules at any time during the period of psoriasis ${ }^{11}$.
Generalized pustular psoriasis (GPP): In the patients of GPP, plaques are also present. Plaque may be either preexisting or may appear once the pustular episode is over. The use of irritating topical agents and sometimes sudden removal of corticosteroids may trigger acute episodes in patients of plaque psoriasis ${ }^{20}$. During acute attacks of GPP, the skin becomes red and sensitive. Some other symptoms like fever, anorexia, and nausea may also be observed. Soon, numerous very fine pustules develop, on the red skin. These pustules produce pus. Finally, these pustules start drying, then skin sheds, leaving behind a shiny and smooth red skin on which fresh pustules start to develop ${ }^{21}$.

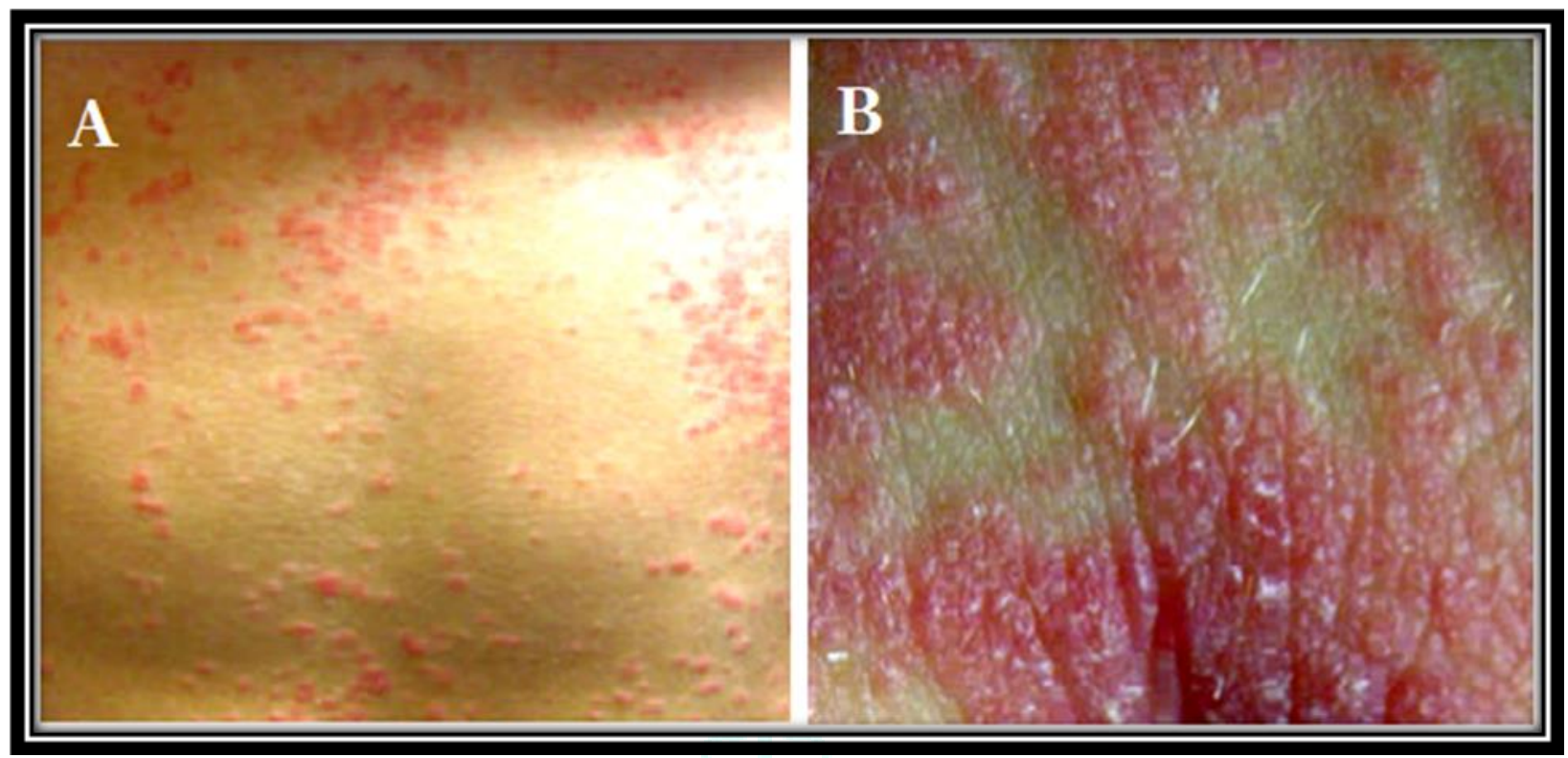

Figure 3. Photographs showing papule and plaque forms of guttate psoriasis.

A. Unmagnified image. B- Magnified image.

Acrodermatitis continua: It is also called as dermatitis repens. It is usually not observed. Usually, it starts when trauma occurs on the tip of a finger or toe ${ }^{22}$. And then pustular eruption can be observed on the fingers and toes.

Palmoplantar pustulosis: The specific features are hyperkeratosis and pustules in groups on the back surface of hands and/or feet. This form is majorly seen in females $(>70 \%)$ and there is a strong association with smoking 23 . Palomar-plantar pustulosis (PPP) generally develops in between 20 to 60 years of age. In this type, big pustules are formed either on the base of the thumb or side of the heel. After sometime pustules become brown colored and start peeling off. After peeling the activeness of PPP reduces for a while.

\subsection{Erythrodermic psoriasis}

Plaque psoriasis is a stable problem. But some triggering factors may transform it into a more extensive form. Plaque psoriasis starts with an inflammatory phase. In this phase majorly erythema and to a limited extent scaling is observed along with itching and fast-developing lesions. In this state of instability sometimes the entire body may be involved. The characteristic features of the erythrodermic phase are generalized redness, a decline of characteristic clinical features of psoriasis, and loss of skin ability to balance homeostasis ${ }^{24}$. Here maximum part of the body gets affected due to intense scaling, itching, and pain. It also causes the chemical imbalance in the body and may lead to serious illness.

\subsection{Nail psoriasis}

In such psoriasis the matrix or bed of nail gets inflamed that leads to characteristic changes in the nail in half of the psoriasis patients. Pitting and distal onycholysis is most commonly observed here 25 . Clinical features may vary from pitting, yellowish discoloration, and paronychia, to subungual hyperkeratosis, onycholysis, and severe onychodystrophy ${ }^{26}$.

\subsection{Psoriatic arthritis}

Psoriatic (PsA) arthritis is found in around 6 to $39 \%$ of psoriasis patients. It is a chronic disorder. It is associated with the inflammation of joints. In the general population it occurs in approximately 0.1 to $0.25 \% 27,28,29$. PsA is more severe than rheumatoid arthritis (RA) but the prognosis is similar ${ }^{30}$. Importantly, $80 \%$ of these patients suffer from nail psoriasis $^{31}$. There is difference in the mechanism of bone resorption and repairing in PsA and RA32.

\section{Causes of Psoriasis}

The two important factors which play crucial role in the development of psoriasis are environment and inheritance. In normal conditions, in three to four weeks skin cells of the epidermis are replaced completely in a continuous manner. But in psoriasis, the process of cell proliferation, both 
formation, and shedding is very fast and the process completes in three to four days. Flares of psoriasis may be triggered by some factors like; infections, stress, skin damage, alcohol intake, and sometimes exposure to intense sunlight. Some medicines such as beta-blockers (Antihypertensive and antianginal drug), lithium, and few antimalarial drugs can also produce the same triggering effect. Abrupt withdrawal of some steroids can also trigger up the flares or worsen psoriasis. Obesity and smoking decrease the responsiveness towards psoriasis treatments ${ }^{33}$.

\section{Pathogenesis}

According to recent studies, autoinflammation has an important role in psoriasis. It could be understood as a condition of sterile inflammation, autoantibodies, and autoreactive $\mathrm{T}$ cells present in the circulation are not supposed to mediate it $34-36$. In the initial stages, lesions may appear because of the recurrent episodes of autoinflammation. These episodes are observed as the neutrophils and cytokines of the interleukin-1 (IL-1) family, like IL-1 $\alpha$, IL-1 $\beta$, and IL-36, burst out. These neutrophils and cytokines have the capacity to initiate the disease ${ }^{35}$. Initial signs start to appear when a complex interaction occurs between genetic and environmental factors (e.g., drugs, stress, smoking, trauma, microorganisms). In genetically predisposed people, during primary stages, the above triggering factors activate the cells of the innate immunity, mostly by effectors such as Toll-like receptors, and then get accumulated in the skin or other affected parts. It also activates keratinocytes, which becomes a part of the immune system, and starts releasing numerous chemokines, also recruits neutrophils and enhances the inflammatory network. In a histopathological study, it has been found that in the primary condition of the disease primarily an infiltrate of innate immunity cells was seen instead of the adaptive immunity cells like T lymphocytes in the skin lesions, as well as recurrent pustular flares. Afterward an accumulation of Thelper (Th) 17 cells takes place in the lesions, which further produce pro-inflammatory cytokines like IL-17 and IL-22 cross-talking with the IL-12/IL-23 axis. In this stage, psoriasis is characterized by papulo-pustulous lesions. In the later stage, which is clinically recognized as plaque psoriasis, the inflammatory process shifts and involves immune response mediated by classical Th1 cells, here predominately Th1 cell-related cytokines such as tumor necrosis factor (TNF)- $\alpha$ and interferon (IFN)- $\gamma$ are observed 35 .

\section{Diagnosis of Psoriasis}

In general practice, psoriasis is diagnosed clinically by physicians, based on the pattern of plaques emergence and dispersion. The biopsy is usually not the tool of diagnosis in psoriasis. Usually to diagnose psoriatic arthritis a rheumatologist's suggestion is enough ${ }^{34}$.

\section{How is psoriasis assessed?}

Assessement of psoriasis is usually done by the physicians based on scores obtained by measuring the severity of psoriasis in skin and joints, affect mood and daily activities, and whether a danger for heart disease is present. These scores used for the assessment are PASI (Psoriatic Area and Severity Index), PGA (Physician Global Assessment), and BSA (Body Surface Area) ${ }^{37}$.

\section{Psoriasis area and severity index (PASI)}

Frederickson and Pettersson were the first to use PASI. The PASI collectively uses 4 body parts for the assessment: the head and neck $(\mathrm{H})$, hands (UL), the trunk (T), and the legs (LL). A numerical score (A) is used to represent the proportion of skin affected by psoriasis in each part: 1 for 0 9 percent, 2 for $10-29$ percent, 3 for $30-49$ percent, 4 for 50-69 percent, 5 for 70-89 percent or 6 for $90-100$ percent. These body parts are examined separately to observe 3 signs of plaque formation - redness (E), thickness/induration (I), and desquamation/scaling (D). These signs are rated on a 5point scale: 0 (no plaque), 1 (mild), 2 (moderate), 3 (severe) or 4 (very severe). The final PASI score may range in between 0 to 72, and the below-mentioned formula is used to calculate it:

PASI $=0.1(\mathrm{EH}+\mathrm{IH}+\mathrm{HH}) \mathrm{AH}+0.2(\mathrm{EUL}+\mathrm{IUL}+\mathrm{HUL}) \mathrm{AUL}+$ 0.3 (ET+IT+HT) AT + 0.4 (ELL+ILL+HLL) ALL 37-39.

\section{Physician global assessment (PGA)}

The PGA is used for the average assessment of lesions in psoriasis. The assessment is based on erythema, scale, and duration. PGA does not involve the quantitative calculation of the affected body surface area or individual lesion ${ }^{40}$. PGA has two forms: the first form is static, here the physician's view at a single point of disease is considered, and the second form is dynamic, here the global improvement of disease from a baseline is assessed by the physician ${ }^{41}$. Here PGA is used on a scale of $0-5$, where: $0=$ clear, $1=$ almost clear, $2=$ mild, $3=$ moderate, $4=$ severe, 5 = very severe.

\section{Body surface area (BSA)}

The "rule of nines" is the most commonly used method for the estimation of the BSA of lesions in psoriasis. It is defined as $9 \%$ coverage of area from each of the following: the head and neck, arms (individually), the anterior and posterior legs, each of 4 trunk quadrants, leaving $1 \%$ for the genitalia. A patient's area of affected hands can also be used to estimate, by assuming that 1 "handprint" reflects around $1 \%$ of $\mathrm{BSA}^{42}$.

\section{Treatment of Psoriasis}

Till date, psoriasis is not curable, only management is possible. For patients with limited disease, just avoidance of provoking factors is sufficient and no treatment is required. Indications for treatment depend upon the localized symptoms (pain, itching, decrease in manual dexterity if the hand is involved, or flexural intertrigo), cosmetic problems (lesions on limb or face), or both. The treatment here aims to decrease the seriousness and spreads of psoriasis so that there is no substantial effect on the patient's professional, personal or social life, or well-being.

The primary treatment in stable plaque psoriasis, in all the conditions, should be topical. Sometimes patients with involvement of 10 percent or more skin may also give good response to topical therapy. But when $>20$ percent part of the body is involved, topical therapy is not sufficient, and systemic therapy is used 43

\section{Topical Treatment}

The commonly used methods of topical treatment are discussed here.

\section{Emollients}

The emollients hydrate the skin and make the hyperkeratinized skin in psoriatic plaques softer. In around $35 \%$ of patients ${ }^{44}$, the use of emollients like yellow paraffin or aqueous cream for at least 2 times in a day, reduces itching, soreness, redness, scaling, and lesional extension. This relief may be due to effects produced in the stratum corneum by reversing the inflammatory consequences which cause damage ${ }^{45}$. Though some greasy emollients, like petrolatum or Aquaphor cream (water in an oil base), are 
more effective these are not well accepted by the patients due to some cosmetic problems, like the shining and stickiness of the skin where these are applied.

\section{Keratolytic Agents}

The most common keratolytic agent is salicylic acid (2-10 $\%)$. It can be used as an ointment with or without coal tar agents or topically used corticosteroids. These ointments soften the layers of scale present on the psoriatic plaques making the removal easier. The absorption of topically used corticosteroids and coal tar agents is also enhanced. Salicylic acid has irritating properties, so it should be used carefully to avoid eye contamination. Effectiveness of salicylic acid as a single agent in psoriasis is not yet reported.

\section{Coal Tar}

Coal tar formulations are usually given with ultraviolet B phototherapy but are capable to remove the plaques of psoriasis if used alone. Because of their unpleasant odor, their use is limited, although they are well tolerated when applied to all but the most unstable lesions, even in low concentrations they can irritate or cause an acneiform eruption on normal skin. It is often added in shampoos to stop the scaling of scalp due to psoriasis. The therapeutically used coal tar preparation when given alone may cause skin cancer in rare conditions $46-48$.

\section{Anthralin}

Anthralin is mostly used in psoriasis for topical treatment in many European and few United States centers. It is commonly used in accordance with the Ingram regime which includes everyday bath once with coal-tar, exposure to ultraviolet B phototherapy, and use of anthralin paste having salicylic acid as an antioxidant to stop the conversion of anthralin to inactive product ${ }^{49}$. On comparing it has been found out that the coal tar-ultraviolet B and coal tarultraviolet B-anthralin regimens are roughly equal in effectiveness, rate of action, and cost 50,51 . There are some problems encountered by anthralin, firstly on oxidation, it converts to colored compounds which produce brown or purple color stains on skin and clothes, second is irritation of perilesional skin due to the formation of free-radicals; by the incorporation of free-radical scavengers and antioxidants both the problems can be reduced 52 . A short-contact regimen has been introduced to overcome the above problems, in this regimen anthralin is removed after one hour of application, it allows the entry into lesional skin and prevents absorption in the perilesional area, providing same efficacy ${ }^{53}$. Currently, this is the preferred regimen, of anthralin use, with efficacy the same as the traditional treatment (which involves an overnight application) and having efficacy the same as that of topical corticosteroids, but fewer adverse effects 54 .

\section{Corticosteroids}

In U. S., topical corticosteroids are mostly used, because of the advantages offered by them like they have short-term efficacy, good patient compliance, and comparatively cheaper ${ }^{55}$. The highly potent topical corticosteroids constantly prove to be effective. Corticosteroids act at a rate equal or faster than the anthralin and coal tar. Corticosteroids do not produce irritation in skin and stain on the skin and clothing, and hence good patient compliance.

All the corticosteroids available are not the same in their efficacy. $0.5 \%$ betamethasone has reported to be more effective than $0.5 \%$ diflorasone diacetate 56 . It is also reported that once-daily application has the same efficacy as the usual twice-daily application with lesser side effects.
Dangerous side effects are not commonly observed in the short period treatment, 56 but topical corticosteroids cause thinning of the skin, striae, hiding of local infections, reduction in pigmentation, and tolerance (tachyphylaxis) to the anti-inflammatory action of the threapy ${ }^{57}$. There are many corticosteroids, including 0.025 to 0.1 percent betamethasone valerate, 0.01 to 0.025 percent fluocinolone acetonide, and 0.025 to 0.1 percent triamcinolone acetonide, which prove to be effective, but their effectiveness does not remain for a very long time 55 . It may also cause psoriasis unstable and susceptible to serious relapse, leading to occasional cases of pustular psoriasis 58. Application of corticosteroid ointment under a plastic occlusive film can improve the efficacy, but local and systemic side effects increases. In adults, application of $30 \mathrm{~g}$ or more once a day of 0.025 percent betamethasone valerate cream under an occlusive dressing causes pituitary-adrenal suppression, 59 and $1.0 \%$ hydrocortisone cream produces a similar effect in infants 60 .

\section{Calcipotriene}

Calcipotriene is derived from vitamin D. Recently this therapy was given license to treat patients of mild-tomoderate plaque psoriasis in Europe and America. It is equal to vitamin $\mathrm{D}$ that has very few effects on calcium metabolism. Observations after the use of oral or topical calcitriol (formerly known as 1 a, 25dihydroxycholecalciferol) it was proved that it can be effectively used for the treatment of psoriasis ${ }^{61}$. Calcipotriene ointment in plaque psoriasis is as effective as a moderately potent corticosteroid ointment like 0.1 percent betamethasone valerate ${ }^{62,63}$.

Calcipotriene ointment (50 $\mu \mathrm{g}$ of calcipotriene per gram) has shown significant progress in $60 \%$ of chronic plaque psoriasis cases when applied twice in a day for a duration of eight-week. The advantage of calcipotriene ointment is that it doesn't produce stains on the clothes. It has a disadvantage of causing little irritation on the face and causes hypocalcemia if double the recommended maximum weekly dose of $100 \mathrm{~g}$ is applied 64 .

\section{Phototherapy And Systemic Treatments}

Topical agents are found successful in most of the patients with limited chronic plaque psoriasis, but approximately 20 percent 55 patient requires some aggressive treatment. Systemic treatment is recommended only when a patient does not responds to the topical treatment and psoriasis is in a severe state. For a more regressive approach, there are the options of phototherapy or systemic treatments. This aggressive approach is recommended only when a large area of the body ( $>20$ percent of the body area) is affected and it is not possible to treat using topical agents because of the inconvenience and cost, or when psoriasis doesn't respond to topical therapy/professionally disables/affects psychologically the patient. All the regimens involve serious effects, and the proportion of benefit to risk must be considered while deciding the therapeutic index of each regimen.

\section{Phototherapy (Ultraviolet B Irradiation)}

Use of $1 \%$ crude coal tar in an aqueous ointment and then exposure to a least erythemogenic dose of ultraviolet $\mathrm{B}$ radiation, gives remission in a minimum $80 \%$ of psoriatic patients. Usually, this remission is controlled by intermittent ultraviolet B phototherapy ${ }^{65}$. In the past decade, the rate of hospitalization for ultraviolet B phototherapy is in favor of outpatient therapy. Among all the therapeutic options available in moderate-to-severe conditions of psoriasis, 
ultraviolet B phototherapy with coal tar offers the best therapeutic index, with a reduction in the chances of skin carcinoma induction 48,66 . The difficulties encountered with this treatment are exposure time to coal tar and ultraviolet B radiation, an objectionable odor of coal-tar formulations, and around 30 treatments are required to attain reasonable benefit. Ultraviolet B phototherapy alone is used regularly in guttate (eruptive papulosquamous) psoriasis patients.

\section{Photochemotherapy}

Photochemotherapy ${ }^{67}$, is also a form of ultraviolet therapy. In this therapy, a photosensitizing drug methoxsalen is combined with ultraviolet A phototherapy (PUVA) in the range of 320 to $400 \mathrm{~nm}$. PUVA has proved to be consistent in controlling the extensive disease. PUVA acts by intercalating the methoxsalen into DNA, then cross-linking of DNA strands which further interferes in DNA synthesis, blocks cell proliferation 68 , and suppresses cell-mediated immune responses in the affected skin ${ }^{69}$. In more than $85 \%$ of patients, it takes around 20 to 30 sittings of drug and ultraviolet A irradiation for skin lesions to disappear ${ }^{67}$. The duration of remission is 6 to 12 months for patients in whom maintenance therapy is terminated after 2 to 3 months ${ }^{70}$. PUVA therapy has very high patient compliance because the response to therapy is high; topical treatments are not required in between the therapy, and the therapeutic schedule is very simple. PUVA has some short-term side effects like nausea, burning, and pruritus in 10 to $20 \%$ of cases, but these side effects are not a problem in the completion of therapy. The issues associated with PUVA on long term use are; an increase in the chances of photodamage to the skin and possibility of cancer due to the exposure to ultraviolet radiation. PUVA enhances the frequency of squamous-cell carcinomas of the $\operatorname{skin}^{71}$ and a relative threat of genital skin cancer in men if the genitals are not protected 72 . The therapeutic index of this therapy could be higher if the accumulative exposure to ultraviolet $A$ radiation has fewer chances of causing carcinomas or severe photodamage- that is, preferably less than 160 treatments ${ }^{73}$. To minimize the cumulative dose of radiation, PUVA could be used in combination with the oral retinoid etretinate ${ }^{74}$. Use of methoxsalen either topically or in bath application is useful but has a high risk of burning the $\operatorname{skin}^{75}$.

\section{Methotrexate}

Methotrexate acts by antagonising folic acid. Methotrexate blocks DNA synthesis, inhibits the proliferation of cells in rapidly dividing tissues like hyperproliferative epidermis in the case of psoriasis and epithelium of gastrointestinal and germinative tissues ${ }^{76}$. Methotrexate also produces an immunosuppressive effect by affecting the mononuclear cells present in the skin, blood, and lymphatic tissues 77 . The cell cycle in psoriatic keratinocytes is very fast (37 hours). The replication of these cells can be inhibited by administering methotrexate orally in 3 doses of 2.5 to $5 \mathrm{mg}$ each at intervals of 12-hour, in combination with the 3 onceweekly doses. This regimen produces minimal side effects ${ }^{78,79}$. Methotrexate in a dose of 10 to $25 \mathrm{mg} /$ week, as once weekly can also be given either orally or parenterally to an adult having $70 \mathrm{~kg}$ of weight ${ }^{80}$. In severe cases of psoriasis, methotrexate is most frequently used when ultraviolet B and coal-tar therapy or PUVA fails either due to poor response, serious side effects, or inconvenience 81 . Before starting methotrexate therapy patient's hematologic conditions and kidney and liver function should be checked and only if these values are normal, methotrexate is recommended. Since $85 \%$ of the methotrexate is excreted in the urine, the adequate renal function becomes necessary, because improper kidney function will lead to a sustained increase in plasma drug concentration, causing acute side effects, like leucopenia and acute gastrointestinal or cutaneous erosions. On long-term use the major side effect was seen with the methotrexate therapy in cirrhosis; so the patients having a history of the hepatic disorder or excessive alcohol intake or with abnormal liver function should avoid taking this drug81. As compared to liver function test and imaging procedures, the liver biopsy reliably identifies patients in whom methotrexate-induced cirrhosis has already developed or is likely to develop ${ }^{81-83}$. Liver-function tests are worth performing initially and at three-month intervals, but the methotrexate guidelines recommend that if continued treatment is proposed, a biopsy of the liver should also be performed before the initiation of treatment 81 . Biopsies should be repeated indefinitely at 1.5 -g intervals of cumulative dosage in the absence of histological evidence of cirrhosis. If methotrexate is present, the drug must be discontinued, even though methotrexate-related cirrhosis may not progress if treatment is continued 84 .

\section{Etretinate}

It is reported that the derivatives of retinoic acid, especially vitamin A, stimulates the differentiation of epithelial cells and inhibits the malignant shifts taking place in the skin and mucous membranes ${ }^{85}$. Retinoids can also increase the delayed hypersensitivity and re-establishes the cells of Langerhans' in psoriatic lesions. Retinoids can both activate and suppress genomic function, including RNA transcription, leading to the differential expression of proteins, which in turn alters clinical disease ${ }^{86}$. Etretinate alone in psoriasis has limited efficacy ${ }^{87}$. In extensive plaque psoriasis, etretinate brings approximately moderate improvement in $50 \%$ of the patients (reduces lesional area by approximately 75 percent) ${ }^{88}$. The use of etretinate is especially beneficial in erythrodermic and acral localized psoriasis which are otherwise difficult to treat 89,90 . Both etretinate and isotretinoin (the more suitable of the two for women of childbearing age) are useful in generalized pustular psoriasis. Etretinate along with PUVA can be given in chronic plaque psoriasis $74,91,92$. This combination reduces the dose of each drug. The etretinate therapy produces cutaneous side effects that are dose-dependent and these are dryness, scaling, erythema, and tenderness. Since etretinate is teratogenic, it should not be used in pregnancy. Since etretinate is a lipid-soluble drug, it gets deposited in the adipose tissue and the liver and can be detected in the plasma even after its discontinuation for up to two years ${ }^{93}$. Systemic therapy with retinoids for one to two years results in skeletal abnormalities, including the periosteal formation of new bone and ligamentous ossification. These changes are proved by radiologic evidence ${ }^{94}$.

\section{Systemic Corticosteroids}

Oral corticosteroid therapy is useful, but it causes Cushing's syndrome on long term use. Another problem is that the psoriasis condition may deteriorate after the discontinuation of corticosteroid therapy, and sometimes the disease may turn into a serious, pustular form resistant to the treatment. It must be restrained for use in erythrodermic psoriatic patients who are acutely ill and should be given for only a short period.

\section{Cyclosporine}

Psoriasis improves rapidly with cyclosporine in two weeks or more. Like other treatments of psoriasis, cyclosporine also does not provide the cure ${ }^{95}$. Cyclosporine decreases the production of interleukin- 2 by blocking the formation of a calcineurin-dependent factor required for the transcription of interleukin-2 gene ${ }^{96,}$, 97 . Interleukin- 2 is important for the 
proliferation of activated $\mathrm{T}$ cells and the production of other T-cell cytokines. Thus, immune amplification requiring interleukin-2 may be suppressed by cyclosporine, preventing the clinical expression of psoriasis. Cyclosporine is allowed for use only in patients with severe psoriasis which is resisting to other regimens (topical therapy, ultraviolet B phototherapy, PUVA, and etretinate). A dose of 3 to $5 \mathrm{mg} / \mathrm{kg} /$ day for one to three months leads to significant improvement in $>60 \%$ of cases ${ }^{95}$. At higher doses improvement is rapid but the risk of adverse effects also increases. Once optimal results are obtained, maintenance therapy with lower doses is generally used. The disease relapses in two to four months if the drug is discontinued.

The side effects of cyclosporine are hypertension and disturbances in renal function, which may be irreversible 98, 99. Cyclosporine increases the possibility of risk of cancer because of its immunosuppressive properties, though it is yet to be proved. It is prudent, however, to avoid combining cyclosporine treatment with phototherapy or other potential mutagenic treatments. Currently, available information indicates that cyclosporine should not be prescribed for more than one year ${ }^{100}$.

\section{Comorbidities in Psoriasis}

Psoriasis is associated with both physical and physiological disorders. Examples of physical co-morbidities are Crohn's disease, psoriatic arthritis, coronary heart disease, stroke, metabolic syndrome (Ischemic heart disease, hypertension, non-alcoholic fatty liver disease, diabetes mellitus, and obesity), and physiological co-morbidities include depression, anxiety, suicide ideation, and alexithymia ${ }^{101}$. It is not clear if cancers, especially lymphoma 102 and skin cancer ${ }^{103}$ have any relation with psoriasis or treatments of psoriasis. The chances of non-melanoma skin cancer increase if the photo chemotherapy is used excessively and could be compounded if cyclosporine is used subsequently. The major concern is the relation of psoriasis with cardiovascular disorders ${ }^{104}$. For patients with mild psoriasis, the risk is not high, but in moderate and severe conditions of psoriasis, a relatively higher risk of almost three times exists ${ }^{105}$. This association is reported to be due to the excessrepresentation of Framingham risk factors in psoriasis patients, but evidence suggests that psoriasis is an independent factor ${ }^{106}$.

\section{References}

1. Willan R, "On Cutaneous Diseases" London: Johnson; 1808

2. Nestle FO, Kaplan DH, Barker J, "Psoriasis" N. Engl. J. Med, 2009; 361:496-509

3. Zangeneh FZ, Shooshtary FS, "Psoriasis - Types, Causes and Medication" http://dx.doi.org/10.5772/54728

4. Christophers E, "Psoriasis-epidemiology and clinical spectrum" Clin Exp Dermatol, 2001; 26:314-20.

5. Wolf-Henning Boehncke, Michael P Schön, "Psoriasis" Lancet, 2015; 386: 983-94

6. aNaldi L, "Epidemiology of psoriasis" Curr Drug Targets Inflamm Allergy, 2004; 3:121-128.

7. aGriffiths CE, Barker JN, "Pathogenesis and clinical features of psoriasis" Lancet, 2007; 370(9583):263-71.

8. bGriffiths CE, Christophers E, Barker JN, Chalmers RJ, Chimenti S, Krueger GG, Leonardi C, Menter A, Ortonne JP, Fry L, "A classification of psoriasis vulgaris according to phenotype" $\mathrm{Br} \mathrm{J}$ Dermatol, 2007; 156: 258-62.

9. Henseler T, Christophers E, "Psoriasis of early and late onset: characterization of two types of psoriasis vulgaris" J Am Acad Dermatol, 1985; 13:450-6.

10. Goodfield M, Hull SM, Holland D, Roberts G, Wood E, Reid S, Cunliffe W, "Investigations of the 'active' edge of plaque psoriasis: vascular proliferation precedes changes in epidermal keratin" Br J Dermatol, 1994; 131:808-13.
11. bNaldi L, Colombo P, Benedetti EP, Piccitto R, Chatenoud L, La Vecchia C, "Study design and preliminary results from the pilot phase of the PraKtis study: self-reported diagnoses of selected skin diseases in a representative sample of the Italian population" Dermatology, 2004; 208:38-42.

12. bGriffiths CE, Christophers E, Barker JN, Chalmers RJ, Chimenti S, Krueger GG, Leonardi C, Menter A, Ortonne JP, Fry L, "A classification of psoriasis vulgaris according to phenotype" $\mathrm{Br} \mathrm{J}$ Dermatol, 2007; 156:258-62.

13. Beylot C, "Clinical aspects of psoriasis" Rev Prat, 2004; 54:19-27.

14. Melski JW, Bernhard JD, Stern RS, “The Koebner (isomorphic) response in psoriasis: associations with early age of onset and multiple previous therapies" Arch Dermatol, 1983; 119:655659.

15. Zanchi M, Favot F, Bizzarini M, Piai M, Donini M, Sedona P, "Botulinum toxin type-A for the treatment of inverse psoriasis" J Eur Acad Dermatol Venereol, 2008; 22:431-6.

16. Telfer NR, Chalmers RJ, Whale K, Colman G, "The role of streptococcal infection in the initiation of guttate psoriasis" Arch Dermatol, 1992; 128:39-42.

17. Naldi L, Peli L, Parazzini F, Carrel CF, "Family history of psoriasis, stressful life events, and recent infectious disease are risk factors for a first episode of acute guttate psoriasis: results of a case-control study" J Am Acad Dermatol, 2001; 44:433-438.

18. Asumalahti K, Ameen, Suomela S, Hagforsen E, Michaëlsson G, Evans J, Munro M, Veal C, Allen M, Leman J, Burden AD, Kirby B, Connolly M, Griffiths CEM,Trembath RC, Kere G, Kere SU, Barker J NWN, "Genetic analysis of PSORS1 distinguishes guttate psoriasis and palmoplantar pustulosis" J Invest Dermatol, 2003; 120:627-632.

19. Mallon E, Bunce M, Savoie H, Rowe A, Newson R, Gotch F, Bunker CB, "HLA-C and guttate psoriasis" Br J Dermatol, 2000; 143:1177-82.

20. Zelickson BD, Muller SA, "Generalised pustular psoriasis. A review of 63 cases" Arch Dermatol, 1991; 127:1339-1345.

21. Viguier M, Allez M, Zagdanski AM, "High frequency of cholestasis in generalized pustular psoriasis. Evidence for neutrophilic involvement of the biliary tract" Hepatology, 2004; 40:452-458.

22. Roelandts $\mathrm{R}$, "The history of phototherapy: something new under the sun?" J Am Acad Dermatol, 2002; 46:926-30.

23. O'Doherty CJ, Macintyre C, "Palmoplantar pustulosis and smoking" 1985; 291:861-864.

24. Balasubramaniam P, Berth-Jones J. Erythroderma: $90 \%$ skin failure. Hosp Med, 2004; 65:100-102.

25. Kahl C, Hansen B, Reich K, "Nail psoriasis--an ignored disorder Pathogenesis, diagnosis and therapy" Hautarzt, 2012; 63:18491.

26. Salomon J, Szepietowski JC, Proniewicz A. Psoriatic nails: a prospective clinical study. J Cutan Med Surg. 2003; 7:317-321.

27. Gelfand JM, Gladman DD, Mease PJ, Smith N, Margolis DJ, Nijsten T, Stern RS, Feldman SR, Rolstad T, "Epidemiology of psoriatic arthritis in the population of the United States" J Am Acad Dermatol, 2005; 53:573.

28. Wilson FC, Icen M, Crowson CS, McEvoy MT, Gabriel SE, Kremers $\mathrm{HM}$, "Incidence and clinical predictors of psoriatic arthritis in patients with psoriasis: a population based study" Arthritis Rheum, 2009; 6:233-239.

29. Gaydukova I, Rebrov A, Nikitina N, Poddubnyy D, "Decreased heart rate variability in patients with psoriatic arthritis" Clin Rheumato, 2012 Jun 7 (Epub ahead of print)

30. Kane D, Stafford L, Bresnihan B, FitzGerald O, "A prospective, clinical and radiological study of early psoriatic arthritis: an early synovitis clinic experience" Rheumatology, (Oxford). 2003; 42:1460-8.

31. Baran R, "The burden of nail psoriasis: an introduction" Dermatology, 2010; 221 Suppl 1:1-5.

32. Rahimi H, Ritchlin CT, "Altered bone biology in psoriatic arthritis" Curr Rheumatol, Rep. 2012; 14:349-57.

33. British association of dermatologists patient information leaflet, psoriasis - an overview, updated October 2018 review, Lay review date October 2018.

34. Angelo Valerio Marzano, Federica Derlino, Emilio Francesco Berti, "Dermatopathology" 2018; 5:14-15, DOI: 10.1159/000486304

35. Christophers E, Metzler G, Röcken M, "Bimodal immune activation in psoriasis" Br J Dermatol, 2014; 170:59-65. 
36. Kastner DL, Aksentijevich I, Goldbach-Mansky R, "Autoinflammatory disease reloaded: a clinical perspective" Cell, 2010; 140:784-790.

37. Agnieszka Bożek, Adam Reich, "The reliability of three psoriasis assessment tools: Psoriasis area and severity index, body surface area and physician global assessment" Adv Clin Exp Med, 2017; 26(5):851-856

38. Fredriksson T, Pettersson U. Oral treatment of pustulosis palmoplantaris with a new retinoid, Ro 10-9359. Dermatologica. 1979; 158:60-64.

39. Berth-Jones J, Grotzinger K, Rainville C, et al. A study examining inter- and intrarater reliability of three scales for measuring severity of psoriasis: Psoriasis area and severity index, physician global assessment and lattice system physician global assessment. Br J Dermatol. 2006; 155:707-713.

40. Robinson A, Kardos M, Kimball AB, "Physician global assessment (PGA) and psoriasis area and severity index (PASI): Why do both? A systematic analysis of randomized controlled trials of biologic agents for moderate to severe plaque psoriasis" J Am Acad Dermatol, 2012; 66:369-375.

41. Feldman S, Krueger G, "Psoriasis assessment tools in clinical trials" Ann Rheum Dis., 2005; 64(Suppl 2):65-68.

42. Spuls PI, Lecluse LL, Poulsen ML, Bos JD, Stern RS, Nijsten T, "How good are clinical severity and outcome measures for psoriasis?: Quantitative evaluation in a systematic review" J Invest Dermato, 2010; 130:933-943.

43. Malcolm W. Greaves, Gerald D. Weinstein, "Treatment of Psoriasis" Drug Therapy, Vol. 332 No. 9

44. Bernstein JE, Parish LC, Rapaport M, Rosenbaum MM, Roenigk $\mathrm{HH} \mathrm{Jr}$, "Effects of topically applied capsaicin on moderate and severe psoriasis vulgaris" J Am Acad Dermatol, 1986; 15:504-7.

45. Ghadially R, Halkier-Sorensen L, Elias PM, "Effects of petrolatum on stratum

corneum structure and function" J Am Acad Dermatol, 1992 26:387-96

46. Young E, "The external treatment of psoriasis: a controlled investigation of the effects of coal tar" $\mathrm{Br}$ J Dermatol, 1970; 82:510-5.

47. Perry HO, Soderstrom CW, Schulze RW, "The Goeckerman treatment of psoriasis" Arch Dermatol, 1968; 98:178-82.

48. Pittelkow MR, Perry HO, Muller SA, Maughan WZ, O’Brien PC, "Skin cancer in patients with psoriasis treated with coal tar: a 25-year follow-up study" Arch Dermatol, 1981; 117:465-8.

49. Ingram JT, "The approach to psoriasis" BMJ, 1953; 2:591-4.

50. MacLennan A, Hellier FF, "The treatment time in psoriasis" Br J Dermatol, 1961; 73:439-44.

51. Ashton RE, Andre P, Lowe NJ, Whitefield M, “Anthralin: historical and current

Perspectives" J Am Acad Dermatol, 1983; 9:173-92.

52. Finnen MJ, Lawrence CM, Shuster S, "Inhibition of dithranol inflammation by free-radical scavengers" Lancet, 1984; 2:112930.

53. Schaefer H, Farber EM, Goldberg L, Schalla W, "Limited application period for dithranol in psoriasis: preliminary report on penetration and clinical efficacy" Br J Dermatol, 1989; 102:571-3.

54. Lowe NJ, Ashton RE, Koudsi H, Verschoore M, Schaefer H, "Anthralin for psoriasis: short-contact anthralin therapy compared with topical steroid and conventional anthralin" J Am Acad Dermatol, 1984; 10:69-72.

55. Liem WH, McCullough JL, Weinstein GD, “Is topical therapy effective for psoriasis: results of survey of U.S. dermatologists" J Invest Dermatol, 1992; 98:602. abstract.

56. Lane AT, Wachs GN, Weston WL, "Once-daily treatment of psoriasis with glucocorticosteroid ointments" J Am Acad Dermatol,1983; 8:523-5.

57. Du Vivier A, "Tachyphylaxis to topically applied steroids" Arch Dermatol, 1976; 112:1245-8.

58. Baker H, Ryan TJ, "Generalised pustular psoriasis: a clinical and epidemiological study of 104 case" Br J Dermatol, 1968; 80:77193.

59. James VH, Munro DD, Feiwel M, "Pituitary-adrenal function after occlusive topical therapy with betamethasone-17-valerate" Lancet, 1967; 2:1059-61.

60. Turpeinen M, "Absorption of hydrocortisone from the skin reservoir in atopic dermatitis" Br J Dermatol, 1991;124:358-60
61. Morimoto S, Yoshikawa K, Kozuka T, et al., "An open study of vitamin D3 treatment in psoriasis vulgaris" Br J Dermatol, 1986; 115:421-9.

62. Kragballe K, "Treatment of psoriasis by the topical application of the novel cholecalciferol analogue calcipotriol (MC 903)" Arch Dermatol, 1989; 125: 1647-52.

63. Kragballe K, Gjertsen BT, De Hoop D, et al, “Double-blind, right/left comparison of calcipotriol and betamethasone valerate in treatment of psoriasis vulgaris" Lancet, 1991; 337:193-6. [Erratum, Lancet 1991;337:988.]

64. Dwyer C, Chapman RS, “Calcipotriol and hypercalcaemia” Lancet, 1991; 338: 764-5.

65. Stern RS, Armstrong RB, Anderson TF, et al., "Effect of continued ultraviolet B phototherapy on the duration of remission of psoriasis: a randomized study" J Am Acad Dermatol, 1986; 15:546-52.

66. Stern RS, Zierler S, Parrish JA, "Skin carcinoma in patients with psoriasis treated with topical tar and artificial ultraviolet radiation" Lancet, 1980; 1:732-5.

67. Melski JW, Tanenbaum L, Parrish JA, Fitzpatrick TB, Bleich HL, "Oral methoxsalen photochemotherapy for the treatment of psoriasis: a cooperative clinical trial” J Invest Dermatol, 1977; 68:328-35.

68. Pathak MA, Fitzpatrick TB, Parrish JA, "Pharmacologic and molecular aspects of psoralen Photochemotherapy" In: Farber E, Cox AJ, Jacobs PH, Nall ML, eds. Psoriasis: proceedings of the second international symposium, New York: Yorke Medical Books, 1977:262-71.

69. Kripke ML, Morison WL, Parrish JA, “Systemic suppression of contact hypersensitivity

in mice by psoralen plus UVA radiation (PUVA)" J Invest Dermatol, 1983; 81:87-92.

70. Stern RS, Fitzpatrick TB, Parrish JA, Honigsmann H, Wolff K, "Oral psoralen Photochemotherapy" In: Roenigk HH Jr, Maibach HI, eds. Psoriasis, 2nd ed. New York: Marcel Dekker, 1991:60323.

71. Stern RS, Laird N, Melski J, Parrish JA, Fitzpatrick TB, Bleich HL "Cutaneous squamous-cell carcinoma in patients treated with PUVA" N Engl J Med, 1984; 310:1156-61.

72. Stern RS, "Genital tumors among men with psoriasis exposed to psoralens and ultraviolet A radiation (PUVA) and ultraviolet B radiation" N Engl J Med, 1990; 322:1093-7.

73. Stern RS, Lange R, “Non-melanoma skin cancer occurring in patients treated with PUVA five to ten years after first treatment" J Invest Dermatol, 1988;91: 120-4. [Erratum, J Invest Dermatol 1989; 92:300.]

74. Fritsch PO, Honigsmann H, Jaschke E, Wolff K, “Augmentation of oral methoxsalen photochemotherapy with an oral retinoic acid derivative" J Invest Dermatol, 1978; 70:170-82

75. Fischer T, "Topical PUVA and bath PUVA" In Roenigk HH Jr, Maibach HI, eds. Psoriasis, 2nd ed. New York: Marcel Dekker, 1991:633-44.

76. McCullough JL, Weinstein G," The action of cytotoxic drugs on cell proliferation in psoriasis" In: Wright NA, Camplejohn RS, eds. Psoriasis: cell

Proliferation, Edinburgh, Scotland: Churchill Livingstone, 1983:34754.

77. Weinstein GD, Jeffes E, McCullough JL, "Cytotoxic and immunologic effects of methotrexate in psoriasis" J Invest Dermatol, 1990; 95:Suppl:49S-52S.

78. Weinstein GD, McCullough JL, Ross PA, “Cell kinetic basis for pathophysiology of psoriasis" J Invest Dermatol, 1985; 85:579. 83.

79. Weinstein GD, Frost $P$, 'Methotrexate for psoriasis: a new therapeutic schedule,"Arch Dermatol, 1971;103:33-8.

80. Peckham PE, Weinstein GD, McCullough JL, "The treatment of severe psoriasis: a national survey" Arch Dermatol, 1987; 123:1303-7.

81. Roenigk HH Jr, Auerbach R, Maibach HI, Weinstein GD, "Methotrexate in psoriasis: revised guidelines" J Am Acad Dermatol, 1988; 19:145-56.

82. Weinstein G, Roenigk H, Maibach H, et al., "Psoriasis-livermethotrexate interactions" Arch Dermatol, 1973;108:36-42.

83. Van Ness MM, Diehl AM, "Is liver biopsy useful in the evaluation of patients with chronically elevated liver enzymes?" Ann Intern Med, 1989; 111:473-8.

84. Zachariae H, "Methotrexate side-effects" Br J Dermatol, 1990; 122:Suppl 36: 127-33 
85. Stadler R, "Three generations of retinoids: basic pharmacological data, mode of action and effects on keratinocyte proliferation and differentiation" In:Greaves MW, Shuster S, eds. Pharmacology of the skin. Vol. 2. Berlin, Germany: SpringerVerlag, 1990:329-58.

86. Elder JT, Fisher GJ, Zhang QY, et al., "Retinoic acid receptor gene expression in human skin" J Invest Dermatol, 1991; 96:425-33.

87. Ellis CN, Hermann RC, Gorsulowsky DC, Goldfarb MT, Voorhees JJ, "Etretinate therapy reduces inpatient treatment of psoriasis" J Am Acad Dermatol, 1987; 17:787-91.

88. Gollnick HPM, Orfanos CE, "Clinical efficacy of etretinate and acitretin: European Experience” In: Roenigk HH Jr, Maibach HI, eds. Psoriasis. 2nd ed. New York: Marcel Dekker, 1991:725-48.

89. Moy RL, Kingston TP, Lowe NJ, "Isotretinoin vs etretinate therapy in generalized pustular and chronic psoriasis" Arch Dermatol, 1985; 121:1297-301.

90. Orfanos CE, Runne U, "Systemic use of a new retinoid with and without local dithranol treatment in generalized psoriasis" $\mathrm{Br}$ J Dermatol, 1976; 95:101-3.

91. Parker S, Coburn P, Lawrence C, Marks J, Shuster S “A randomized doubleblind comparison of PUVA-etretinate and PUVA-placebo in the treatment of chronic plaque psoriasis" $\mathrm{Br} J$ Dermatol, 1984; 110:215-20.

92. Saurat JH, Geiger JM, Amblard P, et al., "Randomized doubleblind multicenter study comparing acitretin-PUVA, etretinatePUVA and placebo-PUVA in the treatment of severe psoriasis" Dermatologica, 1988; 177:218-24.

93. Larsen FG, Jakobsen P, Knudsen J, Weismann K, Kragballe K, Nielsen- Kudsk F, "Conversion of acitretin to etretinate in psoriatic patients is influenced by ethanol" J Invest Dermatol, 1993; 100:623-7.

94. DiGiovanna JJ, Helfgott RK, Gerber LH, Peck GL, “Extraspinal tendon and ligament calcification associated with long-term therapy with etretinate" N Engl J Med, 1986; 315:1177-82.

95. Ellis CN, Fradin MS, Messana JM, et al., "Cyclosporine for plaquetype psoriasis: results of a multidose, double-blind trial" N Engl J Med, 1991; 324:277-84.
96. Wong RL, Winslow CM, Cooper KD, "The mechanism of action of cyclosporine A in the treatment of psoriasis" Immunol Today, 1993; 14:69-74.

97. O’Keefe SJ, Tamura J, Kincaid RL, Tocci MJ, O’Neill EA, “FK-506and CsA-sensitive activation of the interleukin-2 promoter by calcineurin" Nature, 1992; 357:692-4.

98. Gupta AK, Rocher LL, Schmaltz SP, et al., "Short-term changes in renal function, blood pressure, and electrolyte levels in patients receiving cyclosporine for dermatologic disorders" Arch Intern Med, 1991; 151:356-62.

99. Korstanje MJ, Bilo HJG, Stoof TJ, "Sustained renal function loss in psoriasis patients after withdrawal of low-dose cyclosporin therapy" Br J Dermatol, 1992; 127:501-4.

100. Mihatsch MJ, Wolff K, "Consensus conference on cyclosporin A for psoriasis" Br J Dermatol, 1992; 126:621-3.

101. AB Kimball, U Gieler, D Linder, F Sampogna, RB Warren, M Augustin, "Psoriasis: is the impairment to a patient's life cumulative?" JEADV 2010; 24:89-1004, DOI: 10.1111/j.14683083.2010.03705.x

102. Gelfand JM, Neimann AL, Shin DB, Wang X, Margolis DJ, Troxel $\mathrm{AB}$, "The risk of lymphoma in patients with psoriasis " J Invest Dermatol, 2006; 126:2194-201.

103. Lindelof B, Eklund G, Liden S, Stern RS "The prevalence of malignant tumors in patients with psoriasis" J Am Acad Dermatol, 1990; 22:1056-60.

104. Gelfand JM, Neimann AL, Shin DB, Wang X, Margolis DJ, Troxel $A B$ "Risk of myocardial infarction in patients with psoriasis" JAMA, 2006; 296:1735-41.

105. Mallbris L, Akre O, Granath F, et al "Increased risk for cardiovascular mortality in psoriasis inpatients but not in outpatients" Eur J Epidemiol, 2004; 19:225-30.

106. Mrowietz U, Elder JT, Barker J, "The importance of disease associations and concomitant therapy for the long-term management of psoriasis patients" Arch Dermatol Res, 2006; 298:309-18. 